\section{THE WABASH CENTER}

JOURNAL on TEACHING

BOOK REVIEW

\title{
When Getting Along Is Not Enough: Reconstructing Race in Our Lives and Relationships
}

\author{
Maureen Walker \\ Teachers College Press: New York, 2020 \\ (xiii + 135 pages, ISBN 978-0-8077-6337-7, \$31.95)
}

\section{Reviewed By}

Anne-Marie Ellithorpe

Vancouver School of Theology

The events of 2020 have stunned many out of the complacency of, at best, just "getting along." As I write this review, the intertwined crises of racialized hostilities, socio-political injustice, and COVID-19 are provoking not only widespread attention, but a desire on the part of many to be part of the solution, rather than the problem. Yet many remain uncertain as to how to engage in authentic connection. In When Getting Along Is Not Enough, Maureen Walker addresses this need, as she offers relational practices with potential to transform our cultural ways of being and relating. Thus, this profound and insightful book is essential reading for those of us who seek an end to the soul-scarring suffering provoked by "chronic racialized disconnection" (6).

Walker builds on Jean Baker Miller's "self-in-relation" model, with its recognition that disconnection provokes human suffering. Yet while chronic disconnection is typically conceptualized as interpersonal disruption associated with dysfunction within family relationships, Walker explores culture as the agent of chronic disconnection (3). Race is recognized as cultural ideology in action, impacting how we design and execute those systems that shape life within community, whether commercial or political, as well as "how we embody our relationships with each other" (2). Nevertheless, Walker assures us that, despite our having learned to use race as a mechanism of disconnection, we can unlearn those cultural habits. A legacy of stratification has negatively impacted all of society by thwarting our "hardwired yearning" for relationality and authentic connection (115). Yet as we engage in authentic connection, our social imagination is extended, and our vision of who we can be in the world is enlarged.

When Getting Along Is Not Enough is an essentially hopeful book, promoting healthy connections within which "all participants have an opportunity to grow" $(3,83)$. Initially, Walker wanted to call this book Revolutionary Hope, recognizing that to practice hope is to resist, and to subvert alienating and fear-promoting "power-over practices" (9). The book is shaped by the question: "How do we create and sustain healthy connections in a culture marred by chronic disconnection?" (3) We need to ask: "Who, together, might we become?" (6), and to call each other into "fuller experience of our shared humanity" (135). We are encouraged to “intentionally cultivate communities of differentiated allies" (130).

The first half of the book explains race as a cultural organizing dynamic that impacts our everyday interactions and ways of relating. The practice of racial stratification is identified as an ordering of human worth that simultaneously shapes both "implicit associations and explicit behaviors" (4). Issues of belonging, safety, power-over, and social pain are acknowledged and discussed.

The second half of the book focuses on relational skills with the potential to promote both personal transformation and cultural healing. Walker advocates for the skills of disruptive empathy, mindful authenticity, and dynamic mutuality. She challenges race-card games and silencing strategies that suppress authentic conversation. Nine skills for promoting engagement and countering withdrawal and disconnection are articulated.

As theological and religious studies educators, we are well placed to explore and challenge constricting narratives and norms with students, and to foster new narratives and ways of being. We will benefit from engaging with Walker as a conversation partner with the potential to guide us through life-giving conflict that includes shedding our own metaphorical shoes in order to walk in the shoes of another (134). While Walker focuses on American contexts, her insights are valid beyond the United States. The invitation and pathway to transformation is relevant within any context that remains shaped by disconnection. 